\title{
Intimate partner violence and depression in women in China
}

Weiman Yuan, Therese Hesketh

\begin{abstract}
Intimate partner violence (IPV) is recognized as a major public health and social problem globally, with consequences for the individual, family and society. But there is relatively little research on IPV in China. The aim of this study was to estimate the prevalence of different types of violence among women, determine the risk factors and the association with depression. A cross-sectional study among women who had ever been in a relationship, was conducted in six provinces across the three regions of China from July to September 2018 using a self-completion questionnaire developed for the study. The provincial capital and one rural county were purposively selected in each province. Questionnaires were distributed in hospitals and public places. The Center for Epidemiologic Studies Depression Scale (CES-D) was used to measure depression. Data for 2987 women were analyzed. The prevalence of psychological, physical and sexual violence was $77.7 \%$, $40.2 \%$ and $11 \%$ respectively: $52 \%$ had experienced two or three types of violence in their life. After adjustment, risk factors for all-type IPV were: low education attainment, having one child or more, living in western provinces, having an income lower than partner's, and economic pressure. The prevalence of major depression was $18.3 \%$ in women who experienced psychological violence, $23.8 \%$ for physical violence, and $39.3 \%$ for sexual violence. For psychological, physical and sexual violence, the odds ratio for severe depression were 6.62 (95\% CI: 4.49-9.76), 4.31 (3.39-5.48), 5.47 (4.01-7.45), respectively, after controlling for age, occupation, education attainment and residence. There is a clear need to raise awareness about IPV and to develop approaches for prevention and management. The new Domestic Violence Law represents a step in the right direction.
\end{abstract}

\section{Keywords}


Intimate partner violence, depression, women's health, China

\section{Background}

Intimate partner violence (IPV) is now recognized as a major public health and social problem globally (World Health Organization [WHO], 2013). Its importance is acknowledged by its inclusion as an indicator in the fifth Sustainable Development Goal: "Eliminate all forms of violence against all women and girls in the public and private spheres" (United National [UN], 2016). It is also identified as a major risk factor for premature mortality and morbidity in the influential Global Burden of Disease studies (WHO, 2013a).

IPV refers to psychological violence, physical violence, and sexual violence (WHO, 2002), which occurs between partners who are currently, or ever have been in an intimate relationship including marital, cohabiting, or dating relationships. However, a wider definition explicitly expands psychological violence to include control, isolation, using male privilege, and economic abuse (Brickel, 2019). The experience of such violence is much more common in women, with female deaths at the hands of male partners shown to be the most common type of murder for women (National Center for Injury Prevention and Control, Centers for Disease Control and Prevention, 2018). A study conducted by the WHO in 2011 found that approximately one third (30\%) of the world's women have experienced physical and/or sexual violence at the hands of partners (WHO, 2013b).

The negative consequences of IPV are well documented. For victims, apart from physical injuries (Plichta, 2004), mental health problems, especially depression and anxiety, are common (Wathen et al., 2016). Importantly, IPV is often repetitive and may escalate in frequency and severity over time (Carmo et al., 2011; Dicola \& Spaar, 2016). The damage caused by different types of violence and multiple exposures to violence may be cumulative 
in impact, with serious impacts on mental health in the long term (Devries et al., 2013; PicoAlfonso et al., 2006).

IPV also causes harm to families and society. Children exposed to domestic violence are more prone to depression, low self-esteem (Boeckel et al., 2015), and symptoms of posttraumatic stress disorder (Boeckel et al., 2014). They are also more likely to engage in risk behaviors, including violence (Schiff et al., 2014). This is commonly referred to as the "intergenerational transmission of violence" (Ellsberg \& Emmelin, 2014). The economic costs to society have been calculated for some countries. For example, in England and Wales, the most comprehensive estimate of the economic and social cost of domestic violence, including preventive measures, health and victim services, physical and emotional harm, property damage, and police and criminal justice costs, were recently calculated at $£ 66$ billion per year (Rhys et al., 2019).

While awareness of IPV has increased globally, until very recently it has attracted little attention in China. Historically, China has been a strictly patriarchal society, and ideas of female inferiority and male preference are still pervasive, especially in rural areas. Violence in the home is still commonly viewed as a private matter, which should be managed within the family (Chan, 2012). Evidence suggests that women are reluctant to report IPV because of insufficient understanding about what is acceptable behavior, fear of reprisals from the partner, and a sense of shame. The latter is often referred to as "losing face" in Chinese culture (Jahromi, 2016).

There have been few studies of IPV in China. A recent scoping review of all studies found 14 peer-reviewed articles in English and 12 in Chinese-language journals published between 1997 and 2016. Most studies were about specific groups, such as rural women, female migrants, and college students and most focused on physical violence and on marital relationships (T. Yang et al., 2018). Five papers reported the lifetime prevalence of female 
IPV experience in the general population surveys, but these studies did not focus on IPV specifically. The estimates ranged from $25 \%$ to $30 \%$ for psychological violence, $5.4 \%$ to $34 \%$ for physical violence, and $0.7 \%$ to $1.7 \%$ for sexual violence. Nearly all the studies used questionnaires developed for Western settings, directly translated without modifications for cultural differences (T. Yang et al., 2018).

There has been increased interest in IPV in China following the announcement in December 2015 of the first legislation explicitly prohibiting IPV, the Domestic Violence Law of the People's Republic of China. This law defines domestic violence as "physical, psychological or any other infractions between family members characterized by beatings, restraint, deliberate maiming, imposing restrictions on physical liberty, as well as recurrent verbal abuse or intimidation" (Y. Yang, 2016). There are a number of important features of this law: first, the recognition of verbal abuse, intimidation, and restrictions on liberty. Second, the law includes violence against other family members, including children and older family members. It also applies to unmarried cohabitants. Third, domestic violence is deemed a multi-sectoral responsibility of a number of groups, the Women's Federations, civil affairs bureau, the police department, the judiciary, residents' committee, and non-governmental organizations (NGOs). Fourth, refuges for women escaping violence and legal consultation are expected to be provided by local government.

The recent introduction of the domestic violence law, and increased awareness of IPV, means that exploration of IPV is especially timely. This study had five aims: (a) to examine the lifetime prevalence of physical, psychological, and sexual violence among women who have ever been in an intimate relationship; (b) to identify the risk factors for different types of violence; (c) to investigate the prevalence of depression among women who have experienced IPV; (d) to explore the association between IPV and depression; and (e) to 
compare the utility of paper and electronic questionnaires to inform the conduct of future research in this area.

\section{Methods}

\section{Research tool}

A number of scales have been developed to measure IPV. Nearly all have targeted Western populations (Kelsey et al., 1999; Straus et al., 1996). The use of translated versions of these instruments in the Chinese setting is questionable, given the huge cultural differences, as well as the nuances of language. As yet there is no validated tool for IPV in China. Therefore, for this research we developed a questionnaire, drawing on elements of existing tools, carefully adapting the wording of individual items to the Chinese setting where necessary, and adding some questions. To refine the questionnaire, we involved women who had experienced IPV and who were receiving support from a local NGO.

The questionnaire included physical, psychological, and sexual violence and their potential determinants. The eight physical violence questions, hitting, kicking, pushing, slapping, beating-up, throwing things, pulling hair, use of a knife to threaten or harm, and the two sexual violence questions about using force or threats to have sex were drawn from Conflict Tactics Scale-2 (CTS-2) and were ranked by severity on a 4-point Likert-type scale (Straus et al., 1996). For psychological violence, three questions about aggressive expression were drawn from the CTS (Straus, 1979), and two questions about coercive control from the Composite Abuse Scale (Kelsey et al., 1999). At the suggestion of the women from the NGO, another three original items were added: (a) being ignored by the partner for a long time, (b) being stopped from doing things by the partner, and (c) being treated with suspicion and jealousy. Depression was measured by The Center for Epidemiologic Studies Depression Scale (CES-D). The CES-D has been validated for China and it has been widely used in Chinese populations. A Chinese review paper has shown that the Cronbach alpha is 
consistently greater than .8 (Sun et al., 2017). The standard and validated cut-off score is 16 , that is, the score less than 16 indicates no depression and greater than or equal to 16 indicates some degree of depression.

Questions about sociodemographic background included separate identical questions about the partner.

A pilot study was conducted in the gynecology out-patient department of Zhejiang University Women's hospital with a sample of 100 women. All were asked to comment on the ease of understanding and acceptability of the questions and length of the questionnaire overall. All their feedback was discussed by the research team and useful suggestions were incorporated into the final version of the questionnaire.

\section{Procedure}

A cross-sectional study was conducted to include representation of all the regions of China: eastern provinces (Jiangsu, Zhejiang), central province (Henan), and western provinces (Guizhou, Gansu, Sichuan), from July to September 2018. The provinces were selected based on convenience sampling and drawing on our research network and research contacts. The provincial capital and one rural county were purposively selected in each province. Prior to conducting the survey, research assistants were trained to ensure an understanding of the research objectives, content, and questionnaire composition, as well as the sensitivity of the topic. Because of our own experience of using electronic questionnaires in other studies, we decided to use both paper and electronic questionnaires, and to compare the two approaches, in terms of acceptance and utility. Women were approached in a variety of venues: hospitals (especially women's hospitals), as well as in public places, consisting of parks, shopping malls, and libraries. All those approached were asked if they would be willing to complete a questionnaire related to their experience of intimate relationships, including difficulties, and how they managed them. They were specifically told that there 
were some questions related to aggression and violence. If willing, they could then choose to complete the questionnaire either in paper format or on Smartphone (downloaded through a QR code).

All the respondents were informed that the survey was totally anonymous and their privacy would be protected. Written informed consent was obtained by signing the consent box on the front page of the questionnaire.

Ethical approval for this study was obtained from the Medical Ethics Committee of Zhejiang University, School of Public Health.

\section{Measures}

\section{Data analysis}

Descriptive statistics were used for sociodemographic characteristics and the prevalence of different types of violence. The wide range of occupations stated by respondents was dichotomized into "higher occupational status," comprising leadership, managerial, and professional roles and "lower occupational status," comprising worker, farmer, commercial, and service personnel, based on the National Occupational classification (The National Occupational Classification and Occupational Qualification Committee, 1999), with a third category of unemployed, including housewives and the retired. Household structure was categorized into three groups: "Couple," "Couple + Children," and "a family of three generations" with the first as the reference.

Chi-square analysis was used to explore the association between violence experience and each social demographic characteristic. The variables that were found to be significant in the univariate analysis were then included in the binary logistic regression. Logistic regression was used to determine the relationship between the different types of violence and risk of depression with depression as the dependent variable and violence experience as independent variable. For the regression model, adjustment was made for age, occupation, 
education attainment, and residence. Crude odds ratios and adjusted odds ratios with $95 \%$ confidence intervals (CIs) were calculated.

All statistical analyses were performed with SPSS (Version 22.0) and all reported pvalues are two-tailed with statistical significance set at .05.

\section{Results}

\section{Socio-demographic characteristics}

A total of 3,125 women agreed to participate in the study. Of these 128 were excluded for failure to complete key questions, so a total of 2,987 questionnaires were analyzed, 1,346 from hospitals and 1,641 from public areas. Of the women approached, the response rate varied between $43 \%$ and $60 \%$ depending on location, with shopping malls lowest and hospitals highest. We were unable to obtain information on refusers' basic characteristics and reasons for rejection.

Sociodemographic characteristics by residence are shown in Table 1. The mean age of the women was $36.5 \pm 9.5$ (median 35) years and of current partners $38.1 \pm 9.8$ (median 36) years. The overwhelming majority 2,666 (89.3\%) were currently in a married or cohabiting partnership. Over half $(1,759 ; 59 \%)$ were urban residents; women on average had slightly higher education levels than their partners with 986 (33\%) of women and $938(31.4 \%)$ of men having completed higher education, but $82 \%$ of women earned less than their partners. About $960(32.1 \%)$ of women and 1,005 (33.3\%) of men met criteria for high occupational status. Nearly half $(1,308 ; 44.4 \%)$ of the women said the family experienced economic pressure. Around one fifth $(568 ; 19 \%)$ of the women had been in a relationship for more than 15 years; 595 (19.9\%) women lived in three-generation households with parents or parentsin-law; 2,358 (79\%) had one child or more.

\section{Prevalence and pattern of IPV against women}


Tables 2 and 3 show the prevalence and patterns of lifetime experience of IPV in the respondents. Of the total, $79.2 \%$ had experienced psychological, physical, or sexual violence in their lifetime, with $77 \%$ reporting psychological violence, $40.2 \%$ physical violence, and $11 \%$ sexual violence. Lifetime experience of IPV was higher in the western provinces of Guizhou (89.9\%) and Gansu (83.3\%) than in Henan (80.0\%), Sichuan (79.2\%), Zhejiang (72.4\%), and Jiangsu (71.5\%). Most commonly reported forms of psychological violence were shouting (59\%), ignoring (41\%), interfering with personal interests $(40.1 \%)$, and denigrating (33.4\%). Most common forms of physical violence were pushing (29.1\%), throwing things at the partner (24.3\%), and hitting (18.1\%). In terms of sexual violence, using force to have sex (9.2\%) was more common than threats (7.2\%). Almost all types of physical violence were significantly more common in urban than in rural areas.

Figure 1 shows the extent of co-occurrence of psychological, physical, and sexual violence. The overwhelming majority of women who had experienced physical or sexual violence had also experienced psychological violence. Of the total, 1,098 (36.8\%) had experienced psychological violence only, with just 30 (1.0\%) reporting only physical violence and just eight $(0.3 \%)$ only sexual violence; while $259(8.7 \%)$ women reported all three types of violence.

\section{Risk factors for IPV}

Significant risk factors for all types of violence are shown in Tables $4 \& 5$ with crude and adjusted odds ratios, 95\% Confidence Intervals and $P$-values. For psychological violence, significant risk factors after adjustment were age 31 to 40, low occupational status, residence in western provinces, bigger education gap, having an income lower than the partner's, economic pressure and having two children or more.

For physical violence, significant risk factors after adjustment were lower education attainment, residence in western provinces, having an income lower than the partner's, 
economic pressure, having one or more children and the length of relationship longer than 15 years.

For sexual violence, significant risk factors for sexual violence after adjustment were lower education attainment, residence in western provinces, having an income lower than the partner's, economic pressure, having one or more children.

\section{Prevalence of IPV by mode of completion of questionnaire and investigation site}

A total of 2200 paper questionnaires and 787 electronic questionnaires were collected. Respondents who used electronic questionnaires reported a higher prevalence of psychological violence (83.6\%), physical violence (41.3\%) and sexual violence $(13.3 \%)$ compared with $75.6 \%, 39.8 \%$ and $10.2 \%$ respectively. Women over 30 with lower education and occupational status were more likely to have completed paper questionnaires, while women less than 30 with higher education and occupational status were more likely to complete the electronic questionnaire. In addition, the prevalence of physical violence (46.4\%) and sexual violence $(13.5 \%)$ was higher in respondents recruited in public places than in hospitals $(32.7 \%, 8.1 \%$, respectively).

\section{Prevalence of Depression and its association with IPV}

As shown in Table 7, of the total participants, $61.6 \%$ were categorized as having at least mild depression on the CES-D. The proportions of women with depression were $65.5 \%$ among women who had experienced any type of violence, $65.8 \%$ for psychological violence, $69.5 \%$ for physical violence, and $75.8 \%$ for sexual violence. For psychological, physical, sexual violence, and all three types of violence experienced, the odds ratios for depression were $2.57(95 \% \mathrm{CI}=[2.15,3.07]), 2.07[1.76,2.43], 2.26[1.73,2.95]$, and $2.58[2.15,3.10]$ respectively, after controlling for age, occupation, education attainment, and residence.

\section{Discussion}


This is the largest population study to focus specifically on IPV in China, and the first to be conducted after the introduction of the Domestic Violence Law. Our study raises important issues about IPV in China today, in relation to the high prevalence of different types of violence, its determinants, and its association with depression.

Nearly four fifths of our respondents had experienced psychological, physical, or sexual violence at the hands of a partner at some point in their lives. Psychological violence was found to be the most common type of violence with sexual violence the least. The overall prevalences in our study are higher than in other Chinese studies, but comparisons are hindered by different definitions of IPV, different populations, and different measurement methods. For example, the National Women's Federation found a lifetime prevalence of all three types of violence of $24.7 \%$, but only one specific type of physical violence and sexual violence and three types of psychological violence were included (NWF, 2011). Another national study from Chinese Health and Family Life Survey found lifetime prevalences of $27 \%$ physical violence and $33 \%$ psychological violence, but the survey was broad-based with only one question on violence against women (Wang, 2006). There are a number of possible reasons for the higher prevalence in our study: (a) we included questions about a range of different types of violence, rather than just categories of violence, and this is known to increase reporting rates. (b) The timing may also have had an influence. We conducted the survey soon after the change in the law which raised public awareness and increased publicity. The MeToo movement (Wo Ye Shi) has also been active in China and may have raised awareness. (c) Recent improved education and increased economic independence may also have empowered women to respond more openly (Tang \& Lai, 2008). (d) Women reluctant to disclose their experience may have declined to participate.

Among our respondents, 52\% of them had experienced two or three types of IPV. Physical violence was usually accompanied by psychological violence, and sexual violence 
was accompanied by both psychological and physical violence. The overlap of physical and psychological violence is the most common and it is consistent with studies in Nicaragua, South Africa, Pakistan, India, and Brazil (Dunkle et al., 2004; Ellsberg et al., 2000; Farid et al., 2008 Ludermir et al., 2010; Silva et al., 2011). It can be explained by the fact that physical violence is usually accompanied by threats and controlling behaviors (Abeya et al., 2011). However, the overlap of physical, psychological, and sexual violence is arguably the most severe violence type, accounting for $8.9 \%$ of total violence, and this has not been quantified in other studies. Inevitably sexual violence is accompanied by physical attacks, repression, and threats.

Social position, assessed in our study through income, occupation, and education (Anderson, 1997; Yount, 2005), is associated with IPV. Our findings showed women with primary education had a 2.4 -fold increased risk of experiencing physical violence. It is hypothesized that lower education attainment, lower occupational status, and greater economic dependence lead to a higher acceptance of violence (Uzun \& Uzunboylu, 2015) and create barriers to leaving a violent relationship (Kaukinen, 2004), which suggests women with lower education and less financial autonomy are more likely to be exposed to abuse. However, it is well established that women with higher education and income still do experience violence (Ackerson \& Subramanian, 2008; Anderson, 1997; Lawoko et al., 2007). In China, while women's status has improved considerably in the last few decades, traditional values around gender roles do persist. These give men "permission" to be threatening and aggressive toward their wives when they don't comply with demands or carry out what may be regarded as their domestic duties. This may explain why men with lower socioeconomic status are more likely to engage in violence, that is, they still have traditional notions of gender roles. It has also been hypothesized that they have more risk factors specific to 
violence, such as childhood violence experience and substance abuse (Fergusson et al., 2008; Khalifeh et al., 2013).

Power differential between partners and its association with IPV has been widely discussed. However, there is no standard conceptual definition about power differential. Application of resource theory suggests that the person with access to the most resources is presumed to be more powerful (Loving et al., 2004; Tichenor, 1999). Differences in age, education, income, and occupation contribute to the power differential. Couples where there is a difference in education attainment are more likely to hold different expectations about decision making, housework, or intimacy and lead to violence (Anderson, 1997). Our study found that women with a wider education gap with their partner had a 1.27-fold increased risk of experiencing psychological violence and having a lower income was associated with a 1.48-fold of experiencing psychological violence, 1.65 -fold physical violence, and 1.79-fold sexual violence.

In terms of the effects of having children, women with one child had a 1.20-fold to 1.65fold increased risk of experiencing different types of violence, while women with more than two children had 1.77-fold to 2.49-fold risk, which is congruent with other Chinese studies (Xiao \& Feng, 2014) and other countries' studies (Jansen et al., 2016). This may relate to fatigue, the financial stress of raising children and disagreements about how children should be raised. Children can also prevent women from leaving an abusive partner (Sabri et al., 2014).

In addition, consistent with numerous studies, including from China, we found that family economic pressure was significantly associated with IPV (Balabukha et al., 2016; Jewkes et al., 2017). It is well documented that difficult economic conditions may result in anger, frustration, or low self-esteem, leading to tensions which may manifest as violence (Bourgois, 1996; Gelles, 1974; Linsky et al., 1995). 
Our study also showed that the risk of women living in western provinces exposed to physical, sexual, and psychological violence was $2.18,2.04$, and 1.46 times than that in eastern provinces. The most likely explanation is that the western provinces are less developed, education levels are lower, and traditional values in relation to gender are more pervasive (Gao \& Tamara, 2012).

We found that women who experienced IPV were 2.07 to 2.58 times more likely to have depression than women without IPV. Traumatic and psychological stress reactions are considered to be the core mechanisms that explain why IPV might cause depression (Sparrow et al., 2017). Traumatic events such as IPV can cause to fear, stress, and feeling of helplessness, isolation, and powerlessness, which may lead to depression (Beydoun et al., 2012; Devries et al., 2013; Dutton, 1992). Other studies also suggested women with depression are more likely to be in an abusive relationship (Devries et al., 2013; Khalifeh \& Dean, 2010; McPherson et al., 2007). Depression symptoms may influence women's choice to accept partners with poor self-control, conduct disorder, and other factors that predispose partner to commit violence. It seems that the relationship between IPV and depression may be bidirectional: women with IPV exposure are at increased risk of depression, and women with depression symptoms are at increased risk of experiencing IPV.

Finally, a minority of women chose the electronic version of the questionnaire. A few voiced concerns about the potential for leaking of personal information through an electronic device. But younger women with higher education attainment were more likely to accept the electronic version, and these reported consistently higher rates of IPV than those completed with hard copy. Young people are more familiar with electronic questionnaire and enjoy its merit of privacy, tending to share their violence experience as much as possible.

This study has some limitations. First, the validity of self-report may be questionable, especially in relation to recall bias and reluctance to admit something which may be regarded 
as shameful. Second, the investigation sites were purposively and not randomly selected. Third, the low response rate may have resulted in selection bias, but it is not clear whether women who have experienced IPV would be more or less likely to agree to participate in the study. Other plausible reasons for low response rate could be time constraints, concerns about divulging very personal information, and lack of incentives. Fourth, the ability to establish the causal direction of the relationship between IPV exposure and depression was limited because our study was cross-sectional in nature. Fifth, our findings relate to the Chinese setting and inferences to elsewhere should not be made.

\section{Conclusion}

Our results reveal consistently high levels of lifetime prevalence of IPV among women across six provinces in China, significant risk factors, and the high prevalence of depression among victims. To address the high prevalence of IPV, campaigns are needed to raise awareness about the unacceptability and the criminal nature of IPV. In addition, more needs to be done to raise awareness about the new law, including its powers and responsibilities (Rhys et al., 2019). A more supportive environment in the community and in society is needed to change people's attitudes toward IPV. Furthermore, support through local government and NGOs needs to be made available to victims to inform them of their rights, and provide psychological help when necessary, as well as information and access to refuges (Tu, 2017). Importantly, more research, especially using qualitative methods, needs to be undertaken to enable a deeper understanding of the experience of IPV in China, including the reasons why men perpetrate violence, the role of gender equality, and potential interventions to address the problem.

\section{References}


Abeya, S. G., Afework, M. F., \& Yalew, A. W. (2011). Intimate partner violence against women in western Ethiopia: Prevalence, patterns, and associated factors. BMC Public Health, 11, Article 913. https://doi.org/10.1186/1471-2458-11-913

Ackerson, L. K., \& Subramanian, S. V. (2008). State gender inequality, socioeconomic status and Intimate Partner Violence (IPV) in India: A multilevel analysis. Australian Journal of Social Issues, 43(1), 81-102.

Anderson, K. L. (1997). Gender, status, and domestic violence: An integration of feminist and family violence approaches. Journal of Marriage and Family, 59, 655-669.

Balabukha, I., Krishnakumar, A., \& Narine, L. (2016). Intimate partner violence perpetrated by young adult women against men in Ukraine: Examining individual, familial, and cultural factors. Aggressive Behavior, 42, 380-393.

Beydoun, H. A., Beydoun, M. A., Kaufman, J. S., Lo, B., \& Zonderman, A. B. (2012). Intimate partner violence against adult women and its association with major depressive disorder, depressive symptoms and postpartum depression: A systematic review and meta-analysis. Social Science \& Medicine, 75(6), 959-975.

Boeckel, M. G., Blasco, R. C., Grassi, O. R., \& Martinez, M. (2014). Children abuse in the context of intimate partner violence against women: The impact of women's depression and posttraumatic stress symptoms on maternal behavior. Journal of Interpersonal Violence, 29(7), 1201-1227.

Boeckel, M. G., Wagner, A., \& Grassi, O. R. (2015). The effect of intimate partner violence exposure on the maternal bond and PTSD symptoms of children. Journal of Interpersonal Violence, 39(6), 766-773.

Bourgois, P. (1996). In search of masculinity: Violence, respect and sexuality among Puerto Rican crack dealers in East Harlem. The British Journal of Criminology, 36(3), 412427. 
Brickel, R. E. (2019). Preventing interpersonal violence in relationships. https://www.psychalive.org/preventing-interpersonal-violence-relationships/

Carmo, R., Grams, A., \& Magalhães, T. (2011). Men as victims of intimate partner violence. Journal of Forensic and Legal Medicine, 18, 355-359.

Chan, K. L. (2012). Gender symmetry in the self-reporting of intimate partner violence. Journal of Interpersonal Violence, 2, 263-286.

Devries, K. M., Mak, J. Y., Bacchus, L. J., Child, J. C., Falder, G., Petzold, M., Astbury, J., \& Watts, C. H. (2013). Intimate partner violence and incident depressive symptoms and suicide attempts: A systematic review of longitudinal studies. PLOS Medicine, 10, Article e1001439.

Dicola, D., \& Spaar, E. (2016). Intimate partner violence. American Family Physician, 94, $646-651$.

Dunkle, K. L., Jewkes, R. K., Brown, H. C., Gray, G. E., McIntryre, J. A., \& Harlow, S. D. (2004). Gender-based violence, relationship power, and risk of HIV infection in women attending antenatal clinics in South Africa. The Lancet, 363(9419), 1415-1421.

Dutton, M. A. (1992). Understanding women's responses to domestic violence: A redefinition of battered woman syndrome. Hofstra Law Review, 21, 1191-1242.

Ellsberg, M., \& Emmelin, M. (2014). Intimate partner violence and mental health. Global Health Action, 7, Article 25658. https://doi.org/10.3402/gha.v7.25658

Ellsberg, M., Peña, R., Herrera, A., Liljestrand, J., \& Winkvist, A. (2000). Candies in hell: Women's experiences of violence in Nicaragua. Social Science \& Medicine, 51, 15951610.

Farid, M., Saleem, S., Karim, M. S., \& Hatcher, J. (2008). Spousal abuse during pregnancy in Karachi, Pakistan. International Journal of Gynecology \& Obstetrics, 101, 141-145. 
Fergusson, D. M., Boden, J. M., \& Horwood, L. J. (2008). Developmental antecedents of interpartner violence in a New Zealand birth cohort. Journal of Family Violence, 23(8), $737-753$.

Gao, Q. Y., \& Tamara, J. (2012). The incidence of domestic violence and its impact on women's mental health in western rural areas. Journal of Peking University, 44, 379 386.

Gelles, R. J. (1974). The violent home: A study of physical aggression between husbands and wives. SAGE.

Jahromi, M. K. (2016). Prevalence and risk factors of domestic violence against women by their husbands in Iran. Global Journal of Health Science, 8(5), 175-183.

Jansen, H. A. F. M., Nguyen, T. V. N., \& Hoang, T. A. (2016). Exploring risk factors associated with intimate partner violence in Vietnam: Results from a cross-sectional national survey. International Journal of Public Health, 61(8), 923-934.

Jewkes, R., Fulu, E., Naved, R. T., Chirwa, E., Dunkle, K., Haardörfer, R., \& GarciaMoreno, C. (2017). Women's and men's reports of past-year prevalence of intimate partner violence and rape and women's risk factors for intimate partner violence: A multicountry cross-sectional study in Asia and the Pacific. PLOS Medicine, 14(9), Article e1002381.

Kaukinen, C. (2004). Status compatibility, physical violence, and emotional abuse in intimate relationships. Journal of Marriage and Family, 66, 452-471.

Kelsey, H., Mary, S., \& Cynthia, S. (1999). A multidimensional definition of partner abuse: Development and preliminary validation of the composite abuse scale. Journal of Family Violence, 14, 399-415.

Khalifeh, H., \& Dean, K. (2010). Gender and violence against people with severe mental illness. International Review of Psychiatry, 22, 535-546. 
Khalifeh, H., Hargreaves, J., Howard, L. M., \& Birdthistle, I. (2013). Intimate partner violence and socioeconomic deprivation in England: Findings from a national crosssectional survey. American Journal of Public Health, 103(3), 462-472.

Lawoko, S., Dalal, K., Jiayou, L., \& Jansson, B. (2007). Social inequalities in intimate partner violence: A study of women in Kenya. Violence and Victims, 22(6), 773-784.

Linsky, A. S., Bachman, R., \& Straus, M. A. (1995). Stress, culture, and aggression. BookCrafters.

Loving, T. J., Heffner, K. L., Kiecolt-Glaser, J. K., Glaser, R., \& Malarkey, W. B. (2004). Stress hormone changes and marital conflict: Spouses' relative power makes a difference. Journal of Marriage and Family, 66(3), 595-612.

Ludermir, A. B., Lewis, G., Valongueiro, S. A., de Araújo, T. V. B., \& Araya, R. (2010). Violence against women by their intimate partner during pregnancy and postnatal depression: A prospective cohort study. The Lancet, 376, 903-910.

McPherson, M., Delva, J., \& Cranford, J. A. (2007). A longitudinal investigation of intimate partner violence among mothers with mental illness. Psychiatric Services, 58, 675-680. National Center for Injury Prevention and Control, Centers for Disease Control and Prevention. (2018). Intimate partner violence: Consequences. https://www.cdc.gov/injury/index.html[AQ17]

The National Occupational Classification and Occupational Qualification Committee. (1999). The occupational classification code of the People's Republic of China. Labor and Social Security Publishing House.

National Women's Federation. (2011). Survey of women's social status in China(III). http://www.wsic.ac.cn/staticdata/84760.htm

Pico-Alfonso, M. A., Garcia-Linares, M. I., Celda-Navarro, N., Blasco-Ros, C., Echeburúa, E., \& Martinez, M. (2006). The impact of physical, psychological, and sexual intimate 
male partner violence on women's mental health: Depressive symptoms, posttraumatic stress disorder, state anxiety, and suicide. Research Journal of Women's Health, 15, 599-611.

Plichta, S. B. (2004). Intimate partner violence and physical health consequences: Policy and physical health consequences: Policy and practice implications. Journal of Interpersonal Violence, 19(11), 1296-1323.

Rhys, O., Barnaby, A., Stephen, R., \& Miriam, W. (2019). The economic and social costs of domestic abuse. https://www.gov.uk/government/publications/the-economic-and-socialcosts-of-domestic-abuse

Sabri, B., Renner, L. M., Stockman, J. K., Mittal, M., \& Decker, M. R. (2014). Risk factors for severe intimate partner violence and violence-related injuries among women in India. Women \& Health, 54(4), 281-300.

Schiff, M., Plotnikova, M., Dingle, K., Williams, G. M., Najman, J., \& Clavarino, A. (2014). Does adolescent's exposure to parental intimate partner conflict and violence predict psychological distress and substance use in young adulthood? A longitudinal study. Child Abuse \& Neglect, 38(12), 1945-1954.

Silva, E. P., Ludermir, A. B., de Araujo, T. V. B., \& Valongueiro, S. A. (2011). Frequency and pattern of intimate partner violence before, during and after pregnancy. Revista de Saúde Pública, 45, 1044-1053.

Sparrow, K., Kwan, J., Howard, L., Fear, N., \& Macmanus, D. (2017). Systematic review of mental health disorders and intimate partner violence victimisation among military populations. Social Psychiatry and Psychiatric Epidemiology, 52(9), 1059-1080.

Straus, M. A. (1979). Measuring intrafamily conflict and violence: The Conflict Tactics (CT) scales. Journal of Marriage and Family, 41, 75-88. 
Straus, M. A., Hamby, S. L., McCoy, S. B., \& Sugarman, D. B. (1996). The revised Conflict Tactics Scales (CTSZ): Development and preliminary psychometric data. Journal of Family Issues, 17, 283-316.

Sun, X. Y., Li, Y., Yu, C. Q., \& Li, L. M. (2017). Reliability and validity of depression scales of Chinese version: A systematic review. Chinese Journal of Epidemiology, 38(1), 110 116. (In Chinese)

Tang, S. K., \& Lai, P. Y. (2008). A review of empirical literature on the prevalence and risk markers of male-on-female intimate partner violence in contemporary China, 19872006. Aggression and Violent Behavior, 13(1), 10-28.

Tu X \& Lou C. (2017).Risk factor associated with current intimate partner violence at individual and relationship levels: a cross-sectional among married rural migrant women in shanghai, china. BMJ Open, 7(4).

Tichenor, V. J. (1999). Status and income as gendered resources: The case of marital power. Journal of Marriage and Family, 61(3), 638-650.

United National. (2016). Sustainable development goals. https://www.un.org/ sustainabledevelopment/zh/gender-equality/

Uzun, G. O., \& Uzunboylu, H. (2015). A survey regarding of domestic violence against women. Procedia—Social and Behavioral Science, 190, 24-31.

Wang, T. F. (2006). Spousal violence in urban households and its health consequences. Chinese Journal of Sociology, 1, 36-60, 206-207. (In Chinese)

Wathen, C. N., Macgregor, J. C., \& Macquarrie, B. J. (2016). Relationships among intimate partner violence, work, and health. Journal of Interpersonal Violence, 33, 2268-2290.

World Health Organization. (2002). World report on violence and health.

World Health Organization. (2013a). Global health risks: Mortality and burden of disease attributable to selected major risks. 
World Health Organization. (2013b). Global and regional estimates of violence against women: Prevalence and health effects of intimate partner violence and non-partner sexual violence.

Xiao, J., \& Feng, X. T. (2014). Spousal abuse in China and its influencing factors: From a family system perspective. Journal of Social Sciences, 11, 90-99. (In Chinese)

Yang, T., Poon, A. W. C., \& Breckenridge, J. (2018). Estimating the prevalence of intimate partner violence in mainland China-Insights and challenges. Journal of Family Violence, 34(2), 93-105.

Yang, Y. (2016). China's first law against domestic violence to protect wives. http://www.womenofchina.cn/womenofchina/html1/features/rights/1601/42-1.htm

Yount, K. (2005). Resources, family organization, and domestic violence against married women in Minya, Egypt. Journal of Marriage and Family, 67, 579-596. 
Table1. Socio-demographic Characteristics of Respondents By Residence

\begin{tabular}{|c|c|c|c|c|}
\hline \multicolumn{2}{|r|}{ Item } & $\begin{array}{c}\text { City } \\
(n=1228)\end{array}$ & $\begin{array}{c}\text { Rural } \\
(n=1759)\end{array}$ & $\begin{array}{c}\text { Total } \\
(\mathbf{n}=\mathbf{2 9 8 7})\end{array}$ \\
\hline & & $\mathrm{N}(\%)$ & $\mathbf{N}(\%)$ & $\mathbf{N}(\%)$ \\
\hline \multirow{3}{*}{ Age } & $\leq 30$ & $417(34.0)$ & 579(32.9) & $996(33.3)$ \\
\hline & $31 \sim 40$ & $430(35.0)$ & $667(37.9)$ & $1097(36.7)$ \\
\hline & $\geq 41$ & $381(31.0)$ & $513(29.2)$ & $894(29.9)$ \\
\hline \multirow{3}{*}{ Occupation } & Leadership/Manager/Professional & $329(26.8)$ & $631(35.9)$ & $960(32.1)$ \\
\hline & Worker/Farmer/Service personnel & $582(47.4)$ & $584(33.2)$ & $1166(39.0)$ \\
\hline & No job & $317(25.8)$ & $544(30.9)$ & $861(28.8)$ \\
\hline \multirow{4}{*}{$\begin{array}{c}\text { Education } \\
\text { you have } \\
\text { completed }\end{array}$} & Primary education & $433(35.3)$ & $315(17.9)$ & $748(25.0)$ \\
\hline & Secondary education & $539(43.9)$ & $714(40.6)$ & $1253(41.9)$ \\
\hline & Higher Education & $256(20.8)$ & $730(41.5)$ & $986(33.0)$ \\
\hline & No personal income & $135(11.0)$ & $158(9.0)$ & $293(9.8)$ \\
\hline \multirow{3}{*}{$\begin{array}{l}\text { Annual } \\
\text { income }\end{array}$} & $\leq 50, \quad 000 \mathrm{RMB}$ & $717(58.4)$ & $633(36.0)$ & $1350(45.2)$ \\
\hline & 50,000 200,000 RMB & $350(28.5)$ & $861(48.9)$ & $1211(40.5)$ \\
\hline & $\geq 200,000 \mathrm{RMB}$ & $24(6.1)$ & $107(2.0)$ & $131(4.4)$ \\
\hline \multirow{3}{*}{$\begin{array}{l}\text { Partner's } \\
\text { Age }\end{array}$} & $\leq 30$ & $337(27.4)$ & $462(26.3)$ & $799(26.7)$ \\
\hline & $31 \sim 40$ & $443(36.1)$ & $676(38.4)$ & $1119(37.5)$ \\
\hline & $\geq 41$ & $448(36.5)$ & $621(35.3)$ & $1069(35.8)$ \\
\hline \multirow{3}{*}{$\begin{array}{l}\text { Partner's } \\
\text { occupation }\end{array}$} & Leadership/Manager/Professional & $337(27.4)$ & $668(38.0)$ & 1005 (33.6) \\
\hline & Worker/Farmer/Service personnel & $617(50.2)$ & $632(35.9)$ & $1249(41.8)$ \\
\hline & No job & $274(22.3)$ & $459(26.1)$ & $733(24.5)$ \\
\hline \multirow{3}{*}{$\begin{array}{l}\text { Partner's } \\
\text { education } \\
\text { level }\end{array}$} & Primary education & $400(32.6)$ & $252(14.3)$ & $652(21.8)$ \\
\hline & Secondary education & $574(46.7)$ & $823(46.8)$ & $1397(46.8)$ \\
\hline & Higher Education & $254(20.7)$ & $684(38.9)$ & $938(31.4)$ \\
\hline \multirow{2}{*}{ Income gap } & Lower than partner & $1048(85.3)$ & 1401(79.6) & $2449(82.0)$ \\
\hline & Higher than partner & $180(14.7)$ & $358(20.4)$ & $538(18.0)$ \\
\hline \multirow{4}{*}{$\begin{array}{c}\text { Current } \\
\text { relation } \\
\text { ship status: }\end{array}$} & Married/Cohabitant partnership & $1089(88.7)$ & $1577(89.7)$ & $2666(89.3)$ \\
\hline & Separated/Divorced/Widowed & $50(4.1)$ & $54(3.1)$ & $104(3.5)$ \\
\hline & Boyfriend, Girlfriend & $79(6.4)$ & $118(6.4)$ & $197(6.6)$ \\
\hline & Single (previous relationship) & $10(0.8)$ & $10(0.8)$ & $20(0.7)$ \\
\hline \multirow{2}{*}{ Relationship } & $\leq 15$ years & $987(80.4)$ & $1432(81.4)$ & $2419(81.0)$ \\
\hline & $>15$ years & $241(19.6)$ & $327(18.6)$ & $568(19.0)$ \\
\hline \multirow{2}{*}{$\begin{array}{l}\text { Econ. } \\
\text { Pressure }\end{array}$} & Yes & $607(50.0)$ & $701(40.5)$ & $1308(44.4)$ \\
\hline & No & $606(50.0)$ & $1029(59.5)$ & $1635(55.6)$ \\
\hline \multirow{3}{*}{$\begin{array}{c}\text { Child } \\
\text { number }\end{array}$} & 0 & $235(19.1)$ & $394(22.4)$ & $629(21.1)$ \\
\hline & 1 & $520(42.3)$ & $862(49.0)$ & $1382(46.3)$ \\
\hline & $\geq 2$ & $473(38.5)$ & $503(28.6)$ & $976(32.7)$ \\
\hline \multirow{3}{*}{$\begin{array}{c}* \text { Household } \\
\text { structure }\end{array}$} & Couple & $175(14.3)$ & $392(22.3)$ & $567(19.0)$ \\
\hline & Couple+ children & $768(62.5)$ & $1057(60.1)$ & $1825(61.1)$ \\
\hline & A family of three generations & $285(23.2)$ & $310(17.6)$ & $595(19.9)$ \\
\hline \multirow{2}{*}{ Province } & Jiangsu & $104(9.6)$ & $279(17.1)$ & $383(14.0)$ \\
\hline & Zhejiang & $181(16.7)$ & $211(12.8)$ & $392(14.4)$ \\
\hline
\end{tabular}




$\begin{array}{lccc}\text { Henan } & 490(45.3) & 171(10.4) & 661(24.3) \\ \text { Guizhou } & 58(5.4) & 416(25.4) & 474(17.4) \\ \text { Gansu } & 103(9.5) & 340(20.7) & 443(16.3) \\ \text { Sichuan } & 146(13.5) & 223(13.6) & 369(13.6)\end{array}$

* Household structure: In our study, we defined "A family of three generation" is a family consisting of couple, children and parents/parents-in-law.

Table2. The Lifetime Prevalence of Different Types of Violence By Residence

\begin{tabular}{|c|c|c|c|c|c|}
\hline \multicolumn{2}{|r|}{ Item } & Total & City & Rural & $P-$ \\
\hline \multirow{8}{*}{$\begin{array}{c}\text { Psychological } \\
\text { Violence }\end{array}$} & Shouting & 1763(59) & $753(61.3)$ & $1010(57.4)$ & 0.02 \\
\hline & Ignoring & $1226(41)$ & $527(42.9)$ & $699(39.7)$ & 0.001 \\
\hline & $\begin{array}{l}\text { Interfering with personal } \\
\text { activities }\end{array}$ & $1199(40.1)$ & $484(39.4)$ & $715(40.6)$ & 0.78 \\
\hline & Insulting & $999(33.4)$ & $448(36.4)$ & $551(31.3)$ & 0.02 \\
\hline & $\begin{array}{l}\text { Behaving suspicious or } \\
\text { jealous way }\end{array}$ & $708(23.7)$ & $306(24.9)$ & $402(22.8)$ & 0.40 \\
\hline & $\begin{array}{l}\text { Enforcement of social } \\
\text { isolation }\end{array}$ & $571(19.1)$ & $227(18.5)$ & 344(19.6) & 0.06 \\
\hline & $\begin{array}{l}\text { Taking or withholding } \\
\text { earnings }\end{array}$ & $560(18.7)$ & $214(17.4)$ & 346(19.7) & 0.34 \\
\hline & Denigrating & $529(17.7)$ & $256(20.8)$ & $273(15.5)$ & 0.003 \\
\hline \multirow{8}{*}{$\begin{array}{l}\text { Physical } \\
\text { Violence }\end{array}$} & Pushing & $870(29.1)$ & $367(29.9)$ & $503(28.6)$ & 0.01 \\
\hline & $\begin{array}{l}\text { Throwing things at } \\
\text { partner }\end{array}$ & $727(24.3)$ & $298(24.3)$ & $429(24.4)$ & 0.27 \\
\hline & Hitting & $543(18.1)$ & $272(22.1)$ & 271(15.4) & 0.000 \\
\hline & Kicking & $405(13.6)$ & $205(16.7)$ & 200(11.4) & 0.000 \\
\hline & Beating up & $336(11.2)$ & $181(14.7)$ & $155(8.8)$ & 0.000 \\
\hline & Slapping & $282(9.4)$ & $153(12.5)$ & $129(7.3)$ & 0.000 \\
\hline & Pulling hair & $265(8.9)$ & $137(11.2)$ & $117(6.7)$ & 0.000 \\
\hline & Using a knife as a threat & $160(5.4)$ & $61(5.0)$ & $50(2.8)$ & 0.02 \\
\hline \multirow{2}{*}{$\begin{array}{c}\text { Sexual } \\
\text { Violence }\end{array}$} & Using force to have sex & $275(9.2)$ & $128(10.4)$ & $147(8.4)$ & 0.06 \\
\hline & $\begin{array}{l}\text { Using threats to have } \\
\text { sex . }\end{array}$ & $217(7.2)$ & $114(9.3)$ & $103(5.9)$ & 0.003 \\
\hline
\end{tabular}

Table3. The Prevalence And Pattern of Intimate Partner Violence Against Women By Province

\begin{tabular}{cccccc}
\hline \multirow{2}{*}{ Item } & & $\begin{array}{c}\text { Psychological } \\
\text { Violence }\end{array}$ & $\begin{array}{c}\text { Physical } \\
\text { Violence }\end{array}$ & $\begin{array}{c}\text { Sexual } \\
\text { Violence }\end{array}$ & IPV \\
\cline { 3 - 6 } & & $\mathbf{N}(\%)$ & $\mathbf{N}(\%)$ & $\mathbf{N}(\%)$ & $\mathbf{N}(\%)$ \\
\hline \multirow{2}{*}{$\begin{array}{c}\text { Eastern } \\
\text { Province }\end{array}$} & Jiangsu & $272(71.0)$ & $101(26.4)$ & $15(3.9)$ & $274(71.5)$ \\
Central & Zhejiang & $281(71.1)$ & $95(24.2)$ & $26(6.6)$ & $284(72.4)$ \\
Province & Henan & $522(79.0)$ & $261(39.5)$ & $94(14.2)$ & $529(80.0)$ \\
Western & Gansu & $359(81.0)$ & $224(50.6)$ & $59(13.3)$ & $369(83.3)$ \\
Province & Guizhou & $412(86.9)$ & $312(65.8)$ & $87(18.4)$ & $426(89.9)$ \\
& Sichuan & $281(76.2)$ & $114(30.9)$ & $25(6.8)$ & $285(77.2)$ \\
\hline
\end{tabular}


Table4. Association Between Social Demographic Characteristics And Psychological Violence

\begin{tabular}{|c|c|c|c|c|c|}
\hline Psychological Violence & $\mathbf{N}(\%)$ & $\begin{array}{c}\text { cOR } \\
(95 \% \mathrm{CI})\end{array}$ & $P$-value & $\begin{array}{c}\text { aOR } \\
(95 \% \mathrm{CI})\end{array}$ & $P$-value \\
\hline \multicolumn{6}{|l|}{ Women's age } \\
\hline$\leq 30$ & $729(31.4)$ & 1 & & 1 & \\
\hline $31 \sim 40$ & $894(38.5)$ & $1.61(1.31,1.98)$ & 0.000 & $1.20(0.88,1.65)$ & 0.24 \\
\hline$\geq 41$ & $699(30.1)$ & $1.31(1.06,1.62)$ & 0.01 & $0.83(0.50,1.38)$ & 0.48 \\
\hline \multicolumn{6}{|l|}{ Man's age } \\
\hline$\leq 30$ & $583(25.1)$ & 1 & & 1 & \\
\hline $31 \sim 40$ & $890(38.3)$ & $1.44(1.16,1.78)$ & 0.001 & $1.17(0.85,1.61)$ & 0.34 \\
\hline$\geq 41$ & $849(36.6)$ & $1.43(1.15,1.77)$ & 0.001 & $1.35(0.80,2.27)$ & 0.26 \\
\hline \multicolumn{6}{|l|}{ Occupational status } \\
\hline High & $388(16.7)$ & 1 & & 1 & \\
\hline Low & $1934(83.3)$ & $0.97(0.76,1.22)$ & 0.77 & $0.77(0.59,1.01)$ & 0.06 \\
\hline \multicolumn{6}{|l|}{$\begin{array}{c}\text { Partners' occupational } \\
\text { status }\end{array}$} \\
\hline High & $315(13.6)$ & 1 & & 1 & \\
\hline Low & $2007(86.4)$ & $1.58(1.26,1.98)$ & 0.000 & $1.42(1.09,1.85)$ & 0.01 \\
\hline \multicolumn{6}{|l|}{ Residence } \\
\hline Rural & $1362(58.7)$ & 1 & & 1 & \\
\hline City & $960(41.3)$ & $1.01(0.97,1.05)$ & 0.63 & $0.90(0.74,1.11)$ & 0.33 \\
\hline \multicolumn{6}{|l|}{ Province by region } \\
\hline Jiangsu/Zhejiang & $553(23.8)$ & 1 & & 1 & \\
\hline Henan & $522(22.5)$ & $1.51(1.18,1.92)$ & 0.000 & $1.19(0.91,1.57)$ & 0.21 \\
\hline Guizhou/Gansu/Sichuan & $1247(53.7)$ & $1.65(1.35,2.01)$ & 0.000 & $1.35(1.09,1.68)$ & 0.01 \\
\hline \multicolumn{6}{|l|}{ Education } \\
\hline High & $724(31.2)$ & 1 & & 1 & \\
\hline Secondary & $987(42.5)$ & $1.34(1.10,1.63)$ & 0.000 & $0.93(0.64,1.34)$ & 0.68 \\
\hline Primary & $611(26.3)$ & $1.61(1.28,2.04)$ & 0.000 & $1.03(0.80,1.34)$ & 0.82 \\
\hline \multicolumn{6}{|l|}{ Partner's education } \\
\hline High & $672(28.9)$ & 1 & & 1 & \\
\hline Secondary & $1107(47.7)$ & $1.51(1.25,1.83)$ & 0.03 & $1.47(1.01,2.14)$ & 0.04 \\
\hline Primary & $543(23.4)$ & $1.97(1.54,2.53)$ & 0.000 & $1.22(0.94,1.76)$ & 0.13 \\
\hline \multicolumn{6}{|l|}{ Income gap } \\
\hline Higher than partner & $1878(80.9)$ & 1 & & 1 & \\
\hline Lower than partner & $444(19.1)$ & $1.44(1.13,1.83)$ & 0.003 & $1.49(1.16,1.92)$ & 0.002 \\
\hline \multicolumn{6}{|l|}{ Relationship status } \\
\hline Never have a marriage & $166(7.1)$ & 1 & 065 & 1 & 065 \\
\hline Now or ever have a marriage & $2156(92.9)$ & $1.08(0.78,1.50)$ & 0.65 & $1.11(0.72,1.70)$ & 0.65 \\
\hline \multicolumn{6}{|l|}{ Relationship duration } \\
\hline$\leq 15$ & $1863(80.2)$ & 1 & 005 & 1 & 054 \\
\hline$>15$ & $459(19.8)$ & $1.26(0.99,1.58)$ & 0.05 & $0.92(0.69,1.22)$ & 0.54 \\
\hline \multicolumn{6}{|l|}{ Econ. Pressure } \\
\hline
\end{tabular}




\begin{tabular}{cccccc} 
Yes & $1084(47.4)$ & $1.74(1.46,2.09)$ & & $1.62(1.34,1.95)$ & \\
No. of child & & & & 1 & \\
0 & $444(19.1)$ & 1 & & 1 & \\
1 & $1053(45.3)$ & $1.33(1.08,1.65)$ & 0.01 & $1.03(0.73,144)$ & 0.87 \\
$\geq 2$ & $825(35.5)$ & $2.28(1.78,2.91)$ & 0.000 & $1.54(1.04,2.29)$ & 0.03 \\
*Household structure & & & & & \\
Couple & $400(17.2)$ & 1 & & 1 & 0.13 \\
Couple+ children & $1443(62.1)$ & $1.58(1.28,1.95)$ & 0.000 & $1.24(0.94,1.63)$ & 0.24 \\
Three generations & $479(20.6)$ & $1.72(1.31,2.26)$ & 0.000 & $1.24(0.87,1.76)$ & 0.24 \\
\hline
\end{tabular}

* Household structure: In our study, we defined "A family of three generation" is a family consisting of couple, children and parents/parents-in-law.

Table5. Association Between Social Demographic Characteristics And Physical Violence

\begin{tabular}{|c|c|c|c|c|c|}
\hline Physical Violence & $\mathbf{N}(\%)$ & $\begin{array}{c}\text { cOR } \\
(95 \% \mathrm{CI})\end{array}$ & $P$-value & $\begin{array}{c}\text { aOR } \\
(95 \% \mathrm{CI})\end{array}$ & $P$-value \\
\hline \multicolumn{6}{|l|}{ Women's age } \\
\hline$\leq 30$ & $289(24.1)$ & 1 & & 1 & \\
\hline $31 \sim 40$ & $473(39.4)$ & $1.85(1.55,2.22)$ & 0.000 & $1.18(0.89,1.57)$ & 0.24 \\
\hline$\geq 41$ & $439(36.6)$ & $2.36(1.95,2.85)$ & 0.000 & $0.99(0.65,1.52)$ & 0.99 \\
\hline \multicolumn{6}{|l|}{ Man's age } \\
\hline$\leq 30$ & 224(18.7) & 1 & & 1 & \\
\hline $31 \sim 40$ & $443(36.9)$ & $1.68(1.38,2.05)$ & 0.000 & $1.07(0.80,1.45)$ & 0.64 \\
\hline$\geq 41$ & $534(44.5)$ & $2.56(2.11,3.12)$ & 0.000 & $1.31(0.84,2.04)$ & 0.23 \\
\hline \multicolumn{6}{|l|}{ Occupational status } \\
\hline High & $183(15.2)$ & 1 & & 1 & \\
\hline Low & $1018(84.3)$ & $1.18(0.97,1.44)$ & 0.10 & $0.97(0.77,1.22)$ & 0.78 \\
\hline \multicolumn{6}{|l|}{$\begin{array}{c}\text { Partners' occupational } \\
\text { status }\end{array}$} \\
\hline High & $145(12.1)$ & 1 & & 1 & \\
\hline Low & $1056(87.9)$ & $1.48(1.20,1.83)$ & 0.000 & $1.02(0.79,1.31)$ & 0.88 \\
\hline \multicolumn{6}{|l|}{ Residence } \\
\hline Rural & $699(58.2)$ & 1 & & 1 & \\
\hline City & $502(41.8)$ & $1.03(0.94,1.12)$ & 0.53 & $0.90(0.75,1.07)$ & 0.23 \\
\hline \multicolumn{6}{|l|}{ Province by region } \\
\hline Jiangsu/Zhejiang & $196(16.3)$ & 1 & & 1 & \\
\hline Henan & 261(21.7) & $1.93(1.54,2.41)$ & 0.000 & $1.40(1.09,1.80)$ & 0.10 \\
\hline Guizhou/Gansu/Sichuan & $744(61.9)$ & $2.72(2.25,3.23)$ & 0.000 & $2.13(1.73,2.63)$ & 0.000 \\
\hline \multicolumn{6}{|l|}{ Education } \\
\hline High & $258(21.5)$ & 1 & & 1 & \\
\hline Secondary & $508(42.3)$ & $1.92(1.61,2.31)$ & 0.000 & $0.93(0.64,1.34)$ & 0.68 \\
\hline Primary & $435(36.2)$ & $3.92(3.20,4.81)$ & 0.000 & $1.03(0.80,1.34)$ & 0.82 \\
\hline \multicolumn{6}{|l|}{ Partner's education } \\
\hline High & $255(21.2)$ & 1 & & 1 & \\
\hline Secondary & $570(47.5)$ & $1.85(1.54,2.21)$ & 0.000 & $1.47(1.01,2.14)$ & 0.04 \\
\hline Primary & $376(31.3)$ & $3.65(2.95,4.51)$ & 0.000 & $1.22(0.94,1.76)$ & 0.13 \\
\hline \multicolumn{6}{|l|}{ Income gap } \\
\hline Higher than partner & $948(78.9)$ & 1 & 0.000 & 1 & 0.000 \\
\hline Lower than partner & $243(21.2)$ & $1.41(1.17,1.70)$ & 0.000 & $1.63(1.33,2.00)$ & 0.000 \\
\hline
\end{tabular}

Relationship status 


\begin{tabular}{cccccc}
$\begin{array}{c}\text { Never have a marriage } \\
\text { Now or ever have a marriage }\end{array}$ & $\begin{array}{c}58(4.8) \\
1143(95.2)\end{array}$ & $1.93(1.41,2.63)$ & 0.000 & $1.04(0.68,1.59)$ & 0.85 \\
$\begin{array}{c}\text { Relationship duration } \\
\leq 15\end{array}$ & $910(75.8)$ & 1 & & 1 & \\
$>15$ & $291(24.2)$ & $1.74(1.45,2.09)$ & 0.000 & $0.84(0.67,1.06)$ & 0.15 \\
$\begin{array}{c}\text { Econ. Pressure } \\
\text { No }\end{array}$ & $596(50.0)$ & 1 & & & \\
Yes & $595(50.0)$ & $1.46(1.25,1.69)$ & 0.000 & $1.38(1.18,1.63)$ & 0.000 \\
No. of child & & & & 1 \\
0 & $145(12.1)$ & 1 & & & \\
1 & $537(44.7)$ & $2.12(1.71,2.63)$ & 0.000 & $1.32(0.95,1.83)$ & 0.10 \\
$\geq 2$ & $519(43.2)$ & $3.79(3.03,4.74)$ & 0.000 & $1.93(1.35,2.76)$ & 0.000 \\
*Household structure & & & & & \\
Couple & $162(13.5)$ & 1 & & 1 & 0.07 \\
Couple+ children & $780(64.9)$ & $1.87(1.52,2.29)$ & 0.000 & $1.28(0.98,1.67)$ & 0.29 \\
Three generations & $259(21.6)$ & $1.93(1.51,2.46)$ & 0.000 & $1.18(0.86,1.63)$ & 0.29 \\
\hline
\end{tabular}

* Household structure: In our study, we defined "A family of three generation" is a family consisting of couple, children and parents/parents-in-law.

Table6. Association Between Social Demographic Characteristics And Sexual Violence

\begin{tabular}{|c|c|c|c|c|c|}
\hline Sexual Violence & $\mathbf{N}(\%)$ & $\begin{array}{c}\text { COR } \\
(95 \% \mathrm{CI})\end{array}$ & $P$-value & $\begin{array}{c}\text { aOR } \\
(95 \% \mathrm{CI})\end{array}$ & $P$-value \\
\hline \multicolumn{6}{|l|}{ Women's age } \\
\hline$\leq 30$ & $92(27.9)$ & 1 & & 1 & \\
\hline $31 \sim 40$ & $130(39.4)$ & $1.32(0.99,1.75)$ & 0.05 & $0.76(0.51,1.15)$ & 0.20 \\
\hline$\geq 41$ & $108(32.7)$ & $1.35(1.01,1.81)$ & 0.04 & $0.53(0.29,0.97)$ & 0.04 \\
\hline \multicolumn{6}{|l|}{ Man's age } \\
\hline$\leq 30$ & $65(19.7)$ & 1 & & 1 & \\
\hline $31 \sim 40$ & $129(39.1)$ & $1.47(1.08,2.01)$ & 0.02 & $1.48(0.94,2.34)$ & 0.09 \\
\hline$\geq 41$ & $136(41.2)$ & $1.65(1.21,2.25)$ & 0.002 & $1.88(0.98,3.60)$ & 0.06 \\
\hline \multicolumn{6}{|l|}{ Occupational status } \\
\hline High & $59(17.9)$ & 1 & & 1 & \\
\hline Low & $271(82.1)$ & $0.90(0.67,1.22)$ & 0.51 & $0.83(0.59,1.16)$ & 0.28 \\
\hline \multicolumn{6}{|l|}{$\begin{array}{c}\text { Partners' occupational } \\
\text { status }\end{array}$} \\
\hline High & $47(14.2)$ & 1 & & 1 & \\
\hline Low & $283(85.8)$ & $1.07(0.77,1.48)$ & 0.10 & $0.73(0.50,1.07)$ & 0.11 \\
\hline \multicolumn{6}{|l|}{ Residence } \\
\hline Rural & $176(53.3)$ & 1 & & 1 & \\
\hline City & $154(46.7)$ & $1.25(1.02,1.54)$ & 0.03 & $1.08(0.82,1.41)$ & 0.59 \\
\hline \multicolumn{6}{|l|}{ Province by region } \\
\hline Jiangsu/Zhejiang & $41(12.4)$ & 1 & & 1 & \\
\hline Henan & $94(28.5)$ & $2.97(2.02,4.35)$ & 0.000 & $2.13(1.41,3.21)$ & 0.000 \\
\hline Guizhou/Gansu/Sichuan & $195(59.1)$ & $2.57(1.82,3.65)$ & 0.000 & $1.93(1.34,2.79)$ & 0.000 \\
\hline \multicolumn{6}{|l|}{ Education } \\
\hline High & $73(22.1)$ & 1 & & 1 & \\
\hline Secondary & $141(42.7)$ & $1.59(1.18,2.13)$ & 0.000 & $0.93(0.64,1.34)$ & 0.68 \\
\hline Primary & $116(35.2)$ & $2.30(1.68,2.13)$ & 0.000 & $1.03(0.80,1.34)$ & 0.82 \\
\hline
\end{tabular}




\begin{tabular}{|c|c|c|c|c|c|}
\hline High & $58(17.6)$ & 1 & & 1 & \\
\hline Secondary & $157(47.6)$ & $1.92(1.40,2.63)$ & 0.000 & $2.69(1.64,4.4)$ & 0.000 \\
\hline Primary & $115(34.8)$ & $3.25(2.33,4.54)$ & 0.000 & $1.69(1.13,2.53)$ & 0.10 \\
\hline \multicolumn{6}{|l|}{ Income gap } \\
\hline Higher than partner & $246(74.5)$ & 1 & \multirow{2}{*}{0.000} & 1 & \multirow{2}{*}{0.000} \\
\hline Lower than partner & $84(25.5)$ & $1.66(1.27,2.17)$ & & $1.80(1.36,2.39)$ & \\
\hline \multicolumn{6}{|l|}{ Relationship status } \\
\hline Never have a marriage & $25(7.6)$ & 1 & \multirow{2}{*}{0.82} & 1 & \multirow{2}{*}{0.004} \\
\hline Now or ever have a marriage & $305(92.4)$ & $0.95(0.61,1.47)$ & & $2.49(1.33,4.66)$ & \\
\hline \multicolumn{6}{|l|}{ Relationship duration } \\
\hline$\leq 15$ & $259(78.5)$ & 1 & \multirow{2}{*}{0.22} & 1 & \multirow{2}{*}{0.97} \\
\hline$>15$ & $71(21.5)$ & $1.19(0.90,1.58)$ & & $0.99(0.71,1.40)$ & \\
\hline \multicolumn{6}{|l|}{ Econ. Pressure } \\
\hline No & $156(47.7)$ & 1 & \multirow{2}{*}{0.000} & 1 & \multirow{2}{*}{0.03} \\
\hline Yes & $171(52.3)$ & $1.43(1.13,1.80)$ & & $1.30(1.02,1.65)$ & \\
\hline \multicolumn{6}{|l|}{ No. of child } \\
\hline 0 & $40(12.1)$ & 1 & & 1 & \\
\hline 1 & $143(43.3)$ & $1.70(1.18,2.45)$ & 0.004 & $2.10(1.21,3.65)$ & 0.01 \\
\hline$\geq 2$ & $147(44.5)$ & $2.61(1.81,3.76)$ & 0.000 & $2.57(1.43,4.63)$ & 0.002 \\
\hline \multicolumn{6}{|l|}{ *Household structure } \\
\hline Couple & $47(14.2)$ & 1 & & 1 & \\
\hline Couple+ children & $206(62.4)$ & $1.41(1.01,1.96)$ & 0.04 & $0.82(0.55,1.22)$ & 0.32 \\
\hline Three generations & $77(23.3)$ & $1.65(1.12,2.41)$ & 0.01 & $0.86(0.54,1.37)$ & 0.52 \\
\hline
\end{tabular}

Table7. Association Between Depression And Different Type of Violence

\begin{tabular}{|c|c|c|c|c|c|c|}
\hline \multirow{2}{*}{ Item } & \multicolumn{2}{|c|}{ Violence experience } & \multirow{2}{*}{$\operatorname{cOR}(95 \% \mathrm{CI})$} & \multirow{2}{*}{$P$-value } & \multirow{2}{*}{$\operatorname{aOR}(95 \% \mathrm{CI})$} & \multirow{2}{*}{$\begin{array}{c}P- \\
\text { value }\end{array}$} \\
\hline & No & Yes & & & & \\
\hline \multicolumn{7}{|l|}{ Psychological Violence } \\
\hline No depression & $369(55.5)$ & $793(34.2)$ & 1 & \multirow{2}{*}{0.000} & 1 & \multirow{2}{*}{0.000} \\
\hline Depression & $296(44.5)$ & $1529(65.8)$ & $2.41(2.02,2.86)$ & & $2.57(2.15,3.07)$ & \\
\hline \multicolumn{7}{|l|}{ Physical Violence } \\
\hline No depression & $796(44.6)$ & $366(30.5)$ & 1 & \multirow{2}{*}{0.000} & 1 & \multirow{2}{*}{0.000} \\
\hline Depression & $990(55.4)$ & $835(69.5)$ & $1.83(1.57,2.14)$ & & $2.07(1.76,2.43)$ & \\
\hline \multicolumn{7}{|l|}{ Sexual Violence } \\
\hline No depression & $1082(40.7)$ & $80(24.2)$ & 1 & \multirow{2}{*}{0.000} & 1 & \multirow{2}{*}{0.000} \\
\hline Depression & $1575(59.3)$ & $250(75.8)$ & $2.15(1.65,2.79)$ & & $2.26(1.73,2.95)$ & \\
\hline \multicolumn{7}{|l|}{ All types of Violence } \\
\hline No depression & $347(55.8)$ & $815(34.5)$ & 1 & \multirow{2}{*}{0.000} & 1 & \multirow{2}{*}{0.000} \\
\hline Depression & $275(44.2)$ & $1550(65.5)$ & $2.40(2.01,2.87)$ & & $2.58(2.15,3.10)$ & \\
\hline
\end{tabular}

The model in the table were adjusted for age, occupation, education attainment and residence. 


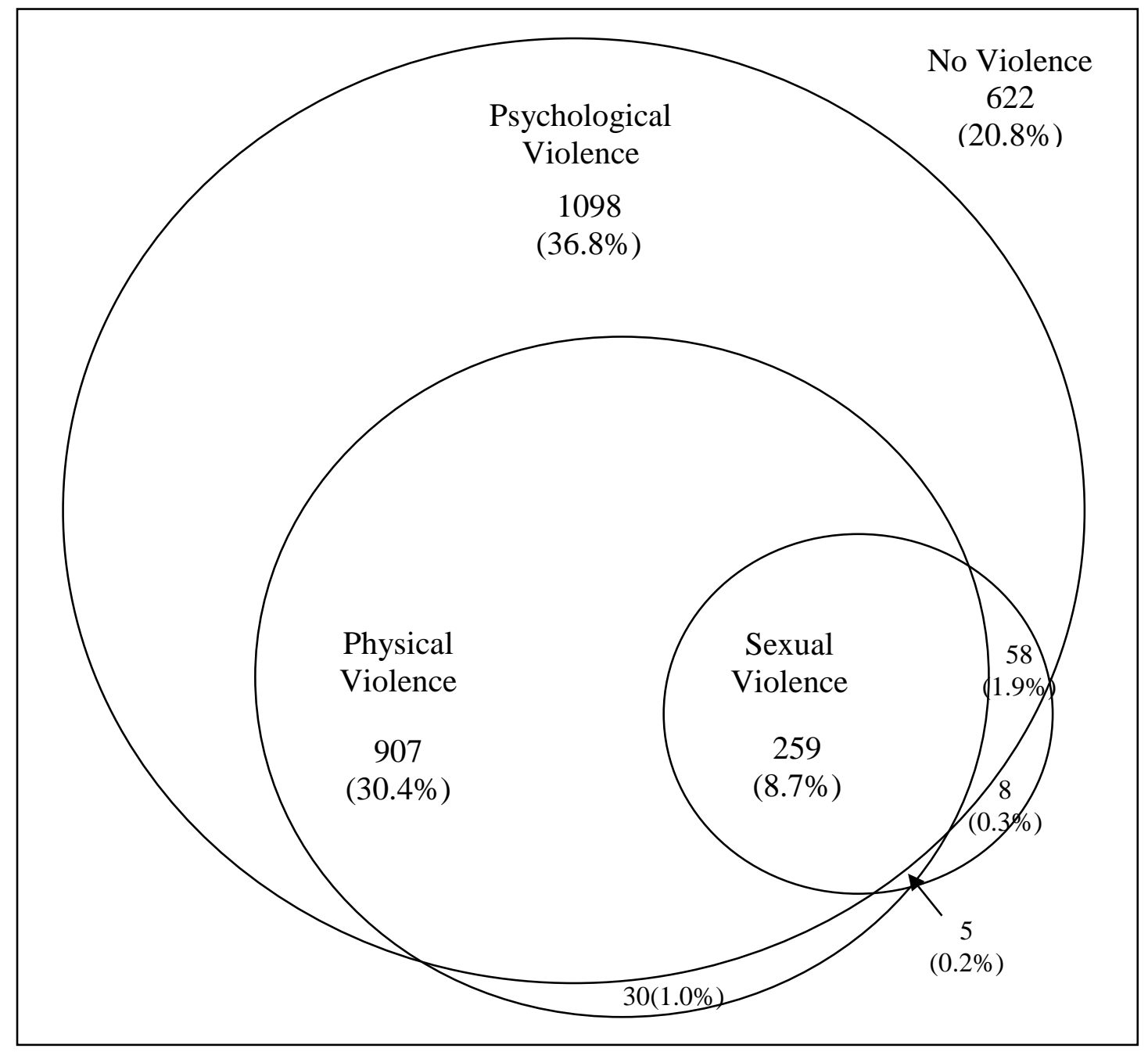

Figure1. The Overlap of Different Type of Violence 